\title{
The Emergence of Dissociative Experiences as a Function of Perceived Stress Among University Students During the COVID-19 Lockdown
}

\section{Szabolcs Garbóczy}

Doctoral School of Health Sciences, University of Debrecen, 4026 Kassai str. 26., Debrecen, Hungary

\section{Anita Szemán-Nagy}

Department of Personality and Clinical Psychology, Institute of Psychology, University of Debrecen, 4032 Egyetem sq. 1., Debrecen, Hungary

\section{Mohamed S. Ahmad}

Faculty of Medicine, University of Debrecen, 4032 Egyetem sq. 1., Debrecen, Hungary

\section{Szilvia Harsányi}

Doctoral School of Health Sciences, University of Debrecen, 4026 Kassai str. 26., Debrecen, Hungary

\section{Dorottya Ocsenás}

Department of Social and Work Psychology, Institute of Psychology, University of Debrecen, 4032

Egyetem sq. 1., Debrecen, Hungary

\section{Viktor Rekenyi}

Faculty of Medicine, University of Debrecen, 4032 Egyetem sq. 1., Debrecen, Hungary

\section{Petra Tischler}

Clinical Center, University of Debrecen, 4032 Egyetem sq. 1., Debrecen, Hungary

\section{Ala'a B. Al-Tammemi}

Doctoral School of Health Sciences, University of Debrecen, 4026 Kassai str. 26., Debrecen, Hungary

László Robert Kolozsvári ( $\square$ kolozsvari.laszlo@med.unideb.hu )

Department of Family and Occupational Medicine, Faculty of Medicine, University of Debrecen, 4032 Móricz Zs. Blvd. 22., Debrecen, Hungary

\section{Research Article}

Keywords: COVID-19, Quarantine, Dissociative Experience, Mental Wellbeing, Perceived Stress, University Students, Hungary, Pandemic

Posted Date: January 18th, 2021

DOI: https://doi.org/10.21203/rs.3.rs-145432/v1 
License: (c) (i) This work is licensed under a Creative Commons Attribution 4.0 International License. Read Full License 


\section{Abstract}

Background: The findings of previous literature showed that epidemics and the associated control measures can increase the level of stress experienced by people. The phenomenon of dissociation has been investigated by many studies, and some have found that stress and trauma may play a central role in its development. In our research study, we examined the effect of COVID-19 lockdown on the mental health of students at the University of Debrecen in Hungary. We investigated whether or not the changes caused by the pandemic induced stress among students and whether or not it was accompanied by an increase in the number of dissociative experiences.

Methods: A questionnaire-based cross-sectional study was conducted at the University of Debrecen in Hungary in the period April 30 - May 15, 2020, to assess levels of perceived stress as well as dissociative experiences among students at the time of the official nationwide lockdown. Our survey has adopted the Perceived Stress Scale (PSS) and the Dissociative Experiences Scale (DES). A total of 1320 students have enrolled in our study.

Results: Our results showed a high level of perceived stress among the students during the pandemic and lockdown. This elevation was found to have a significant correlation with the emergence of dissociative experiences among both the Hungarian and the international students. Also, these changes were significant among males and females and in all subscales. Female students' levels of dissociative experiences were higher than of male students on all subscales and in both groups (Hungarian and international).

Conclusion: According to our findings, the COVID-19 pandemic, and the quarantine situation increased the perceived stress level which has played a significant role in the development of dissociative experiences among the students. The increased frequency of dissociative experiences entails a higher risk to the appearance of dissociative disorders; thus, it is crucial to create a safety net for university students who are susceptible to high levels of stress.

\section{Introduction}

The COVID-19 outbreak which originated from Wuhan province in China and followed by the extensive spread across the world has already resulted in more than 88 million patients and over 1.9 million deaths so far [1]. Upon declaring the first cases of COVID-19 in Hungary on March 4, 2020, the Hungarian government introduced immediate and stringent measures that aimed to contain the outbreak, slow down the viral spread, and to provide sufficient time for the national health care system to prepare for patient care during the pandemic [2]. These control measures included the closure of borders and airports, restrictions on leaving home except for vital reasons, an officially ordered home quarantine, working from homes, the introduction of online education, mandatory shopping time zones for senior citizens whose age 65 or above, and the obligation to wear a face mask on public transport and in all shops. The nationwide lockdown was declared by the Hungarian government on March 28, 2020 [2]. 
Although the mortality rate seems to be high in Hungary (13.95\%), the number of those who were infected has been kept low compared to other European nations, courtesy of these strict and timely measures. For example, the number of infections per 100,000 capita per some European countries: Spain 530.6, Italy 397.1, France 243.2, Germany 233.0, United Kingdom 465.3, and Hungary 42.2 as of June 27, 2020 [3].

The fear of the pandemic and its measures (e.g. quarantine) can have psychological impacts on the population and in several cases these need to be addressed urgently. More recent studies found that the most vulnerable group of society in terms of stress and anxiety is the students' population [4-7]. It had been already established that the stark shift from face to face classes to online distance education and the social separation that comes with it, can pose a negative impact on anxiety and stress levels of students [6-8].

The concept of dissociation has undergone a significant transformation over time. Bernstein and Putnam [9] defined it as "dissociation is a lack of the normal integration of thoughts, feelings, and experiences into the stream of consciousness and memory'. Nowadays, dissociative experiences are usually conceptualized as a spectrum ranging from normal to pathological. On one end of this spectrum, is dissociation that is considered to be adaptive, for example, daydreaming; while on the other end there are the more serious, pathological forms of dissociation such as amnesia and identity problems [10]. Complicating the situation is that what has been widely considered to be an adaptive dissociation (under the influence of acute traumatic event dissociation can be considered as an adaptive defense mechanism); under the influence of trauma or extreme stress level can also be turned into pathological because of the lack of integration. In acute cases, dissociation is usually associated with some kind of a traumatic event. So in acute cases, we can find peritraumatic dissociation which is a set of experiences that occur during the period surrounding trauma, this includes a changed perception of place, time, and one's self [11].

Waller and Ross [12] found that pathological dissociation affects $3.3 \%$ of the population. In the same study, examining twins, it was found that the observed variance could be related to shared environmental influences which were approximately $45 \%$ and the rest of the variance could be related to non-shared environmental influences. Johnson et al. found in another study the following prevalence of dissociative disorders in the general population: depersonalization disorder (prevalence: $0.8 \%$ ), dissociative identity disorder (prevalence: 1.5\%), dissociative amnesia (prevalence: 1.8\%), and dissociative disorder not otherwise specified (prevalence: 4.4\%) [13]. According to Maaranen et al. [14], in a 3-year Finnish followup study, just a small part of the people had elevated levels of dissociative experiences constantly.

Given that extreme stress promotes the development of dissociative experiences, especially the pathological forms, it is easy to conclude that the number of dissociation symptoms increases due to either acute (natural disasters) or prolonged (e.g. dictatorships) stress. This is especially noticeable when circumstances and the future are unpredictable, unforeseeable, in which case people are even more precarious in a state of loss of control [15]. For example, Brooks et al. [16] found that an officially ordered 
quarantine or lockdown may be a measure that significantly increases an individual's level of perceived stress, which may affect the experienced dissociative symptoms.

As part of a larger research project that aimed at examining the impacts of the COVID-19 pandemic on the mental health status of both Hungarian students (who were ordered to leave the dormitories and join their families), and international students (who were far away from their homeland, and thus at the risk of struggling to receive relevant support if needed e.g. psychological, psychiatric, medical) at the University of Debrecen. In our present study, we specifically assessed the level of perceived stress among the students as well as the emergence of dissociative experiences that might be associated with it. We hypothesized that the introduction of the lockdown restrictions in Hungary and the closure of universities and dormitories will result in an increased level of perceived stress among the students. Therefore we assumed an increase in both pathological and adaptive subscales and the overall scale of dissociation as a function of perceived stress. We also considered the possibility that the international students who were quarantined in Hungary, far from their homelands and families, may report higher levels of perceived stress and increased dissociative experiences.

\section{Methods And Materials}

\subsection{Study Design and Setting}

This was a questionnaire-based cross-sectional study that was conducted in the period April 30 - May 15, 2020. The self-completion questionnaire was administered to students in a web-based format using the Google Form ${ }^{\circledR}$ survey tool. The study was conducted at the University of Debrecen, which is one of the largest higher education institutions in Hungary. Debrecen city is considered the educational and cultural hub of Eastern Hungary. Data were collected during the most stressful period of the COVID-19 pandemic in Hungary, i.e. nationwide lockdown

\subsection{Study Participants and Sampling}

The target population of our study was the students at the University of Debrecen. The students were approached through social media platforms (Facebook $\left.{ }^{\circledR}\right)$ as well as the official administration system at the university (Neptun system). Both Hungarian and International students were recruited to participate in our survey and the questionnaire was both in Hungarian and English languages. All participants should have been at least 18 years or older and enrolled in a study program at the University of Debrecen to be eligible for participation.

\subsection{Survey Instruments}

Our survey questionnaire has solicited anonymous responses using brief sociodemographic items and international scales, namely, Perceived Stress Scale (PSS) $[17,18]$, and the Dissociative Experiences Scale (DES) $[9,19]$. The sociodemographic questions were about age, gender, years of education, faculty/study program, and place of residence since the outbreak. 
The Dissociative Experiences Scale (DES) $[9,20]$ is a scale developed by Carlson and Putnam to measure dissociative experiences. During the design of DES, the scale was defined as a continuum of dissociative experiences based on the number and frequency [9]. On this continuum, healthy people report rarely and few dissociative experiences (i.e. when rarely and few different dissociative experiences the person experiences, they can even be healthy). According to Vanderlinden the dissociative experiences, that are considered to be healthy, originate from the adaptive dissociative mechanisms which are absorption and loss of control [21].

As the scale moving towards the other endpoint, more and more individuals can be found who have clinical symptoms, they report diverse and varied dissociative experiences [9]. The number and frequency of symptoms make it likely that the clinical condition will appear. The DES is a series of 28 statements of questions that describe dissociative symptoms in general and could initially be marked on a scale (DES-I) [9] how often a person feels the given symptom in a part of their everyday life, and then on a $0-100 \%$ scale, which increasing per $10 \%$, the same could be done (DES-II) [20]. The average of the summation gives how many points the person has completed on DES. The higher it is, the more likely is the presence of dissociative symptoms. Some dissociative activity can also be measured among healthy people, which was found to be 4.38 points in the first survey that assessed it [9]. This value was found to be the highest in dissociative identity disorder (57.1), while it was found to be the second-highest in posttraumatic stress disorder PTSD (31.3) [22]. The test has three subscales: amnestic dissociation (International: Cronbach $a=0,868$; Hungarian: Cronbach $a=0,832$ ); absorption and imagination (International: Cronbach $a=0,896$; Hungarian: Cronbach $a=0,863$ ); and depersonalization and derealization (International: Cronbach $a=0,868$; Hungarian: Cronbach $a=0,861$ ) [20].

The Perceived Stress Scale (PSS) [17] was designed to measure the level of stress in the average population, those who have completed at least the 11th grade of school. It asks about the stressful situations people noticed in the preceding month. It contains ten statements that respondents can answer on a 5-point (0-4) Likert scale. The PSS has four positive statements, the score of which must be reversed, and then all answers' points must be added together. Previous literature found that for normal test-takers between the age of 18 and 29, the mean PSS score was 14.2 [17]. Among the Hungarian university students, we used the Hungarian version of the PSS [18], which contains 14 statements, and it can be scored on a 5-point (0-4) Likert scale to assess how typical a certain behavior was in the last month. The Hungarian version of the test was validated in 2006. The mean score of the normal population was 25.4 and the tool had a Cronbach's alpha of 0.88 [18].

\subsection{Data Analyses}

Data were extracted from Google Forms ${ }^{\circledR}$ as an Excel sheet then we used SPSS ${ }^{\circledR}$ (v.25) and RStudio statistical software packages to analyze the data. Descriptive and summary statistics were presented as appropriate. To assess the differences in dissociative subscales among Hungarian and international students, we used variance analysis (with Bonferroni test as a posthoc test) or the nonparametric Kruskal-Wallis test (along with Mann-Whitney tests with lowered significance level). Also, the Kolmogorov-Smirnov normality test has been used to assess the distribution of the perceived stress 
levels of the groups when more than 50 people in a group and the Shapiro-Wilk test in the case when there were less than 50 people in a group. The Spearman's rank correlation was employed to assess the correlation between sex, age, group (domestic/international students), perceived stress, and dissociative experiences. Moreover, we ran a multiple linear regression analysis with the perceived stress and age as the independent variables and the dissociative experiences score as the dependent variable.

\subsection{Ethical Considerations}

Our study was carried out following the code of ethics of the World Medical Association (Declaration of Helsinki). Written informed consent was obtained from all participants. Also, ethical permission was obtained from the Hungarian United Ethical Review Committee for Research in Psychology (Reference number: 2020-45). All participants were informed about the study objectives, and their participation was voluntary. There was no reward upon participation.

\section{Results}

\subsection{Sociodemographic Profile of Respondents}

We received a total of 1320 responses, of which 1314 valid (complete) responses were included in the final analysis. Of the overall cohort $(n=1314), 72.1 \%(n=948)$ and $27.9 \%(n=366)$ were Hungarian and international students, respectively. The mean age $( \pm S D)$ of Hungarian students was 24.99 years $( \pm 8.07)$ and for the international students was 22.68 years $( \pm 3.87)$. Among the Hungarian students $(n=948)$, most students were studying at non-health faculties $(n=690,72.8 \%)$, while among the international students $(n=366)$ most students were enrolled in health-related programs $(n=232,63.4 \%)$. See Table 1 for more details.

Table 1

Sociodemographic Profile of Respondents $(n=1314)$

\begin{tabular}{|lll|}
\hline & $\begin{array}{l}\text { Hungarian } \\
(\boldsymbol{n}=948)\end{array}$ & $\begin{array}{l}\text { International } \\
(\boldsymbol{n}=366)\end{array}$ \\
\hline Gender & $719(75.84 \%)$ & $220(60.11 \%)$ \\
\hline Female & $229(24.16 \%)$ & $146(39.89 \%)$ \\
\hline Male & $24.99( \pm 8.07)$ & $22.68( \pm 3.87)$ \\
\hline Age (mean \pm SD) & & \\
\hline Faculty/Study Program & $258(27.22 \%)$ & $232(63.39 \%)$ \\
\hline Health-related & $690(72.78 \%)$ & $134(36.61 \%)$ \\
\hline Non health-related & $948(100 \%)$ & $344(93.99 \%)$ \\
\hline Stayed in Hungary during the pandemic & & \\
\hline
\end{tabular}




\subsection{Perceived Stress and Dissociative Experiences Scores}

As the PSS comprised a different number of items in the Hungarian and English versions, we calculated the average score on the tests per question and test. Among the Hungarian students, the whole PSS average score was $30.1( \pm 11.68)$ and per question average score was $2.15( \pm 0.83)$. For the International students, the results were $23.62( \pm 8.34)$ and $2.36( \pm 0,83)$; respectively. Both populations showed immensely elevated levels of stress during the pandemic and the curfew compared to normal test values. Also, to test the hypothesis, firstly, we converted the dissociation scales to category variables. On the scale and subscales of the dissociative experiences, we looked at the mean and standard deviation of the Hungarian and international sub-samples. See Table 2.

Table 2

Statistical indicators of DES subscales among Hungarian and International students

\begin{tabular}{|lllllllll|}
\hline Students & \multicolumn{2}{c}{ Amnestic } & \multicolumn{2}{c|}{ Absorption } & \multicolumn{2}{c|}{ Depersonalization } & \multicolumn{2}{c|}{$\begin{array}{l}\text { Overall Scale / } \\
\text { Total Scale }\end{array}$} \\
\cline { 2 - 9 } & Mean & SD & Mean & SD & Mean & SD & Mean & SD \\
\hline Hungarian & 10,06 & 13,71 & 29,89 & 21,25 & 10,43 & 16,63 & 18,55 & 15,53 \\
\hline International & 11,69 & 16,31 & 30,73 & 23,52 & 13,53 & 19,79 & 21,03 & 18,22 \\
\hline SD: Standard Deviation & & & & & & & \\
\hline
\end{tabular}

Based on the mean and standard deviation, we created a normative range for our sample. This made the Hungarian and international groups comparable. Based on this the results became classifiable into 'under normative', 'normative', and 'above normative' ranges. The perceived stress scale was compared within these groups. Moreover, we used variance analysis (with Bonferroni test as posthoc test) or nonparametric Kruskal-Wallis test (along with Mann-Whitney tests with lowered significance level) according to the distribution of the groups. The distribution of the perceived stress level of the groups was inspected by the Kolmogorov-Smirnov normality test if there were more than 50 people in the group, and the Shapiro-Wilk test was used in the case when there were less than 50 people in the group. We considered it worthwhile to fit the values into a multiple linear regression model. First, we correlated the variables with Spearman's rank correlation (Table 3). The variables were the following: gender, age, group (Hungarian vs international), perceived stress, and dissociative experiences. Since there were significant correlations between the dissociative experiences and the perceived stress and age, we ran a multiple linear regression with the perceived stress and age as the independent variables and the dissociative experiences as the dependent variable. The model was significant $(F(2 ; 1232)=132,65 ; p<$ 0,$\left.001 ; R^{2}=0,176\right)$, and all the independent variables fit in the model: both the age $(t=-3,896 ; p<0,001 ; \beta=$ $-0,104)$, and the perceived stress $(t=14,478 ; p<0,001 ; \beta=0,385)$. 
Table 3

Correlations between gender, age, group, stress, and dissociative experiences

\begin{tabular}{|c|c|c|c|c|c|}
\hline Variables & Gender & Age & Group & Stress & Dissociative Experiences \\
\hline Gender & 1 & 0,015 & . & 0,06 & $-0,037$ \\
\hline Age & 0,015 & 1 &,$- 064^{\star}$ &,- 210 ** &,$- 270 * \star$ \\
\hline Group & . &,$- 064^{\star}$ & 1 &, $076 * \star$ & 0,033 \\
\hline Stress & 0,06 &,$- 210 * *$ &, 076 ** & 1 &, $448 * *$ \\
\hline Dissociative experiences & $-0,037$ &,$- 270 \star \star$ & 0,033 &, $448 \star \star$ & 1 \\
\hline
\end{tabular}

The variance analyses have shown that there were significant differences in all cases. As can be seen in Table 4, Fig. 1, and Fig. 2, the perceived stress level and the dissociative experiences grow together. Also, the higher levels of perceived stress, regardless of gender or group, increase the probability of dissociative experiences on all subscales and in terms of the total score. In Table 4 it is also prominent that the female students' levels of dissociative experiences are higher than of male students on all subscales and in both groups (Hungarian and international). 
Table 4

DES subscales per nationality and gender

\begin{tabular}{|c|c|c|c|c|c|c|}
\hline Students & Subscales & Gender & $\begin{array}{l}\text { Value of test } \\
\text { statistic }(F / \\
\left.\chi^{2}\right)\end{array}$ & $\begin{array}{l}\text { Degree of } \\
\text { Freedom } \\
(d f)\end{array}$ & $\begin{array}{l}\text { Significance } \\
\text { Level }\end{array}$ & $\begin{array}{l}\text { Post- } \\
\text { hoc } \\
\text { Tests }\end{array}$ \\
\hline \multirow[t]{16}{*}{ International } & \multirow[t]{6}{*}{ Amnestic } & Total & 29.99 & $1 ; 364$ & $<0,001$ & $\begin{array}{l}p \leq \\
0,014\end{array}$ \\
\hline & & Male & 14.42 & 2 & $<0.001$ & $\begin{array}{l}0.015^{1} ; \\
<\end{array}$ \\
\hline & & & & & & $\begin{array}{l}0.001^{2} \\
0.026^{3 *}\end{array}$ \\
\hline & & Female & 19.41 & 2 & $<0.001$ & ${ }_{<}^{0.042^{1}}$ \\
\hline & & & & & & \\
\hline & & & & & & $0.001^{3 *}$ \\
\hline & \multirow[t]{3}{*}{ Absorption } & Total & 53.53 & $1 ; 364$ & $<0,001$ & $<0.001$ \\
\hline & & Male & 22.56 & $1 ; 144$ & $<0.001$ & $\begin{array}{l}\leq \\
0.022\end{array}$ \\
\hline & & Female & 31.01 & 2 & $<0.001$ & $\begin{array}{l}<.001 * \\
0.00\end{array}$ \\
\hline & \multirow[t]{4}{*}{ Depersonalization } & Total & 62.72 & $1 ; 364$ & $<0.001$ & $\begin{array}{l}p \leq \\
0,039\end{array}$ \\
\hline & & Male & 21.07 & $1 ; 144$ & $<0.001$ & $\begin{array}{l}< \\
0.001^{1} ;\end{array}$ \\
\hline & & & & & & $\begin{array}{l}0.001^{2} \\
0.732^{3}\end{array}$ \\
\hline & & Female & 27.27 & $1 ; 218$ & $<0.001$ & $\begin{array}{l}\leq \\
0.009\end{array}$ \\
\hline & \multirow[t]{3}{*}{ Total } & Total & 35.48 & $1 ; 364$ & $<0.001$ & $<0.001$ \\
\hline & & Male & 21.28 & $1 ; 144$ & $<0.001$ & $\leq$ \\
\hline & & Female & 37.84 & 2 & $<0.001$ & $\begin{array}{l}<.001 * \\
0 .\end{array}$ \\
\hline Hungarian & Amnestic & Total & 87.83 & 2 & $<0,001$ & $\begin{array}{l}< \\
0.001 *\end{array}$ \\
\hline
\end{tabular}




\begin{tabular}{|c|c|c|c|c|c|c|}
\hline Students & Subscales & Gender & $\begin{array}{l}\text { Value of test } \\
\text { statistic }(F / \\
\left.\chi^{2}\right)\end{array}$ & $\begin{array}{l}\text { Degree of } \\
\text { Freedom } \\
(d f)\end{array}$ & $\begin{array}{l}\text { Significance } \\
\text { Level }\end{array}$ & $\begin{array}{l}\text { Post- } \\
\text { hoc } \\
\text { Tests }\end{array}$ \\
\hline & & Male & 23.76 & $1 ; 227$ & $<0.001$ & $\begin{array}{l}< \\
0.001^{1} ; \\
< \\
0.001^{2} ; \\
0.185^{3}\end{array}$ \\
\hline & & Female & 70.76 & 2 & $<0.001$ & $\begin{array}{l}<.001 * \\
0 .\end{array}$ \\
\hline & \multirow[t]{3}{*}{ Absorption } & Total & 50.16 & 2 & $<0.001$ & $\begin{array}{l}< \\
0.001 *\end{array}$ \\
\hline & & Male & 22.06 & $1 ; 227$ & $<0.001$ & $\begin{array}{l}0.078^{1} ; \\
< \\
0.001^{2} ; \\
< \\
0.001^{3}\end{array}$ \\
\hline & & Female & 106.37 & 2 & $<0.001$ & $<.001 *$ \\
\hline & \multirow[t]{3}{*}{ Depersonalization } & Total & 117.17 & 2 & $<0.001$ & $\begin{array}{l}< \\
0.001 *\end{array}$ \\
\hline & & Male & 27.09 & $1 ; 227$ & $<0.001$ & $<0.05$ \\
\hline & & Female & 126.5 & $1 ; 717$ & $<0.001$ & $<0.001$ \\
\hline & \multirow[t]{3}{*}{ Total } & Total & 106.64 & 2 & $<0.001$ & $<, 001 *$ \\
\hline & & Male & 10.79 & $1 ; 227$ & $<0.001$ & $\begin{array}{l}0.582^{1} \\
0.048^{2} \\
0.015^{3}\end{array}$ \\
\hline & & Female & 100.57 & 2 & $<0.001$ & $\begin{array}{l}< \\
0.001 *\end{array}$ \\
\hline & \multicolumn{6}{|c|}{$\begin{array}{l}\text { * Significance level is reduced to } 0.0167 \text { after Kruskal-Wallis test in the Mann-Whitney } \\
\text { post-hoc tests }\end{array}$} \\
\hline & \multicolumn{6}{|c|}{${ }^{1}$ Significance between the under normative and normative groups } \\
\hline & \multicolumn{6}{|c|}{${ }^{2}$ Significance between the under normative and above normative groups } \\
\hline & \multicolumn{6}{|c|}{${ }^{3}$ Significance between the normative and above normative groups } \\
\hline
\end{tabular}

To compare the Hungarian and international groups, the Mann-Whitney test was used. In perceived stress, there was a significant difference between the two groups $(W=149410 ; p<0.001)$. The international 
students perceived a higher stress level. There was no significant difference in the total dissociation experiences level of the two groups $(W=163460 ; p=0.104)$.

\section{Discussion}

In our study, and as we hypothesized, we found that under the altered conditions triggered by the COVID19 pandemic the perceived stress levels of the university students were immensely high. Related to this, we also found a higher level of dissociative experiences. The frequency of dissociative experiences varies with perceived stress, the higher the perceived stress the more dissociative experiences are reported. In the case of PSS, we found that international students quarantined in Hungary had significantly higher values. The reason for that phenomenon could be funding problems (is the family able to afford their education even in the changed circumstances?); inadequate information; uncertainty (even the status of Hungarian students was uncertain initially and that only got direr when it came to international students); pressure to make significant decisions (should they travel home?); and in addition to not being able to receive support from their family and friends living far away from them, they were also unable to care for their loved ones in need.

Regarding the dissociative experiences, although we found a significant correlation on all subscales, namely that the higher the perceived stress the more likely the dissociative experiences appear, we did not find a significant difference between the Hungarian and international students, although the frequency of the dissociative experiences was higher among foreigners. What could cause this phenomenon? There may be a reason to use other coping mechanisms if we take the theory that dissociation is a coping mechanism. It is also conceivable that international students have better resilience than Hungarians in terms of dealing with psycho-traumas, but we did not collect information about childhood period and resiliency, so it remains a theory [23].

As in previous literature, authors have found that traumatization or extreme stress, for example, a high level of perceived stress, proportionally increases the number of dissociation symptoms [24-27]. This does not necessarily mean that the increased number of dissociative symptoms are due to the stress the students are currently experiencing, but it is conceivable that the stress they have experienced in the past will add up to the situations they are currently experiencing [28]. It can also mean that they can respond to stressful situations in a variety of ways and the way the students used in our study, is the dissociation to cope with harmful situations [25]. Where this will lead in the future, whether it will develop into a psychiatrically relevant illness, we cannot be sure. Birmes et al. [29] and Candel and Merckelbach [30] have addressed the relationship between acute stress and PTSD and found a correlation between the two.

In our study, we found significant differences between the dissociative experiences according to gender: female students report higher levels of dissociative symptoms. Previous studies have found significant gender-difference in dissociation experiences. Females scored higher than males on the DES [31, 32], although, other studies do not confirm that there is significant gender-difference in dissociative 
experiences [33, 34]. The female-to-male ratio is 9:1 in dissociative disorders [35] because dissociative disorders are very strongly associated with childhood trauma (especially sexual abuse) which is more common in girls [36], and the internalizing pathologies (eg. dissociation, depression) are also more common in women [37].

To the best of our knowledge, this is the first study that investigated the perceived stress level and its connection with the dissociative symptoms among university students during the COVID-19 pandemic. Yet, our study is not without limitations, most prominently the language barrier as English is not the mother tongue of all international students and this could compromise their ability to fill out the questionnaire properly. However, it can be said that fluency in English is an entry requirement at the University of Debrecen and students have been doing their studies in English too; thus, we can assume that they speak English on a high academic level. Another limitation is about using a convenience sampling method which may affect the generalizability of our results to all university students in the country.

\section{Conclusion}

According to our findings, the COVID-19 pandemic, and the quarantine situation increased the perceived stress level which plays a significant role in the development of dissociative experiences. The increased frequency of dissociative experiences entails a higher risk to the appearance of dissociative disorders. It is of paramount importance that students would be properly informed, that the restrictions and measures imposed are clear and, if necessary, that relevant support is available and easily accessible. It is crucial to create a safety net for university students who are susceptible to increased stress levels and thus the number of pathological dissociative experiences under critical circumstances. As international students perceived more stress, all universities must be aware of this issue to develop protocols that will help the students during stressful situations, especially those who are away from their families and homeland.

\section{Abbreviations}

COVID-19 - Coronavirus Disease 2019

DES - Dissociative Experiences Scale

PSQ - Perceived Stress Questionnaire

PSS - Perceived Stress Scale

PTSD - Post Traumatic Stress Disorder

WHO - World Health Organization

\section{Declarations}




\section{Ethics approval and consent to participate:}

The work described has been carried out following the code of ethics of the World Medical Association (Declaration of Helsinki). Ethical permission was obtained from the Hungarian Ethical Review Committee for Research in Psychology (Reference number: 2020-45). All methods were done in accordance with the institutional guidelines and conforming to the ethical standards of the declaration of Helsinki. All participants were informed about the study and written informed consent was obtained from all participants.

\section{Consent for publication:}

Not Applicable

\section{Availability of data and materials:}

The datasets generated and/or analyzed during the current study are not publicly available due to compliance with institutional guidelines but they are available from the corresponding author (LRK) on a reasonable request.

\section{Competing interests:}

The authors declare that they have no competing interests

\section{Funding:}

This research project did not receive any specific grant from funding agencies in the public, commercial, or not-for-profit sectors.

\section{Authors' contributions:}

All authors SG, ASN, MSA, SH, DO, VR, PT, ABA, and LRK have worked on the study design, text writing, revising, and editing of the manuscript. DO, SG, and VR have done data management and extraction, data analysis. Drafting and interpretation of the manuscript were made in close collaboration by all authors (SG, ASN, MSA, SH, DO, VR, PT, ABA, and LRK). All authors have read and approved the submitted version of the manuscript.

\section{Acknowledgments:}


We would like to thank the University of Debrecen and the Hungarian United Ethical Review Committee for Research in Psychology for making our study possible. We also would like to provide our thanks and appreciation to all students who participated in our study. ABA is currently supported by the Tempus Public Foundation's scholarship at the University of Debrecen

\section{References}

1. World Health Organization. Coronavirus disease (COVID-19) outbreak situation. [Online]. 2020. https://www.who.int/emergencies/diseases/novel-coronavirus-2019. Accessed 11 Jan 2020.

2. About Hungary. Hungary - COVID-19. [Online]. 2020. http://abouthungary.hu/coronavirus/. Accessed 27 Jun 2020.

3. Centers for Disease Control and Prevention. COVID-19 situation update worldwide. [Online]. 2020. https://www.ecdc.europa.eu/en/geographical-distribution-2019-ncov-cases. Accessed 27 Jun 2020.

4. Kamal NM, Othman N. Depression, Anxiety, and Stress in the time of COVID-19 Pandemic in Kurdistan Region, Iraq. Kurdistan J Appl Res - KJAR. 2020;5:37-44.

5. Ozamiz-Etxebarria N, Dosil-Santamaria M, Picaza-Gorrochategui M, Idoiaga-Mondragon N. Stress, anxiety, and depression levels in the initial stage of the COVID-19 outbreak in a population sample in the northern Spain. Cad Saude Publica. 2020;36:e00054020.

6. Al-Tammemi AB, Akour A, Alfalah L. Is It Just About Physical Health? An Online Cross-Sectional Study Exploring the Psychological Distress Among University Students in Jordan in the Midst of COVID-19 Pandemic. Front Psychol. 2020;11:562213.

7. Akour A, Al-Tammemi AB, Barakat M, Kanj R, Fakhouri HN, Malkawi A, et al. The Impact of the COVID19 Pandemic and Emergency Distance Teaching on the Psychological Status of University Teachers: A Cross-Sectional Study in Jordan. Am J Trop Med Hyg. 2020;103:2391-9.

8. Van D, McLaws M-L, Crimmins J, Maclntyre CR, Seale H. University life and pandemic influenza: attitudes and intended behaviour of staff and students towards pandemic (H1N1) 2009. BMC Public Health. 2010;10:130.

9. Bernstein EM, Putnam FW. Development, reliability, and validity of a dissociation scale. J Nerv Ment Dis. 1986;174:727-35.

10. LYNN CD. Adaptive and Maladaptive Dissociation: An Epidemiological and Anthropological Comparison and Proposition for an Expanded Dissociation Model. Anthropol Conscious. 2005;16:16-49. doi:https://doi.org/10.1525/ac.2005.16.2.16.

11. Schauer M, Elbert T. Dissociation following traumatic stress: Etiology and treatment. Zeitschrift für Psychol Psychol. 2010;218:109-27.

12. Waller NG, Ross CA. The prevalence and biometric structure of pathological dissociation in the general population: Taxometric and behavior genetic findings. Journal of Abnormal Psychology. 1997;106:499-510. 
13. Johnson JG, Cohen P, Kasen S, Brook JS. Dissociative disorders among adults in the community, impaired functioning, and axis I and II comorbidity. J Psychiatr Res. 2006;40:131-40.

14. Maaranen P, Tanskanen A, Hintikka J, Honkalampi K, Haatainen $K$, Koivumaa-Honkanen $H$, et al. The course of dissociation in the general population: a 3-year follow-up study. Compr Psychiatry. 2008;49:269-74.

15. Canan F, North CS. Dissociation and disasters: A systematic review. World J psychiatry. 2019;9:8398.

16. Brooks SK, Webster RK, Smith LE, Woodland L, Wessely S, Greenberg N, et al. The psychological impact of quarantine and how to reduce it: rapid review of the evidence. Lancet. 2020;395:912-20. doi:10.1016/S0140-6736(20)30460-8.

17. Cohen S. Perceived stress in a probability sample of the United States. In: The social psychology of health. Thousand Oaks, CA, US: Sage Publications, Inc; 1988. p. 31-67.

18. Strauder A, Thege BK. Az Észlelt Stressz Kérdőív (PSS) Magyar Verziójának Jellemzői. Mentálhigiéné És Pszichoszomatika. 2006;7:203-216.

19. Dóra P-F, Gyöngyi A, Csilla B, Zsófia K, Sarolta K. Kérdőívek, becslőskálák a klinikai pszichológiában. 3rd edition. Budapest: Semmelweis Kiadó; 2012.

20. Carlson EB, Putnam FW. Dissociation: An update on the Dissociative Experience Scale. Univ Oregon Sch Bank. 1993;6:16-27.

21. Vanderlinden J, Van Dyck R, Vandereycken W, Vertommen H. The Dissociation Questionnaire (Dis-G): development, reliability and validity of a new self-reporting Dissociation Questionnaire. Acta Psychiatr Belg. 1994;94:53-4.

22. Chu JA. Rebuilding shattered lives: Treating complex PTSD and dissociative disorders, 2 nd ed. Hoboken, NJ, US: John Wiley \& Sons Inc; 2011.

23. Zolkoski SM, Bullock LM. Resilience in children and youth: A review. Child Youth Serv Rev. 2012;34:2295-303. doi:https://doi.org/10.1016/j.childyouth.2012.08.009.

24. Marčinko D, Jakovljević M, Jakšić N, Bjedov S, Mindoljević Drakulić A. The Importance of Psychodynamic Approach during COVID-19 Pandemic. Psychiatr Danub. 2020;32:15-21.

25. Morgan CA 3rd, Hazlett G, Wang S, Richardson EGJ, Schnurr P, Southwick SM. Symptoms of dissociation in humans experiencing acute, uncontrollable stress: a prospective investigation. Am J Psychiatry. 2001;158:1239-47.

26. Carlson EB, Rosser-Hogan R. Trauma experiences, posttraumatic stress, dissociation, and depression in Cambodian refugees. Am J Psychiatry. 1991;148:1548-51.

27. Panasetis $P$, Bryant RA. Peritraumatic versus persistent dissociation in acute stress disorder. $J$ Trauma Stress. 2003;16:563-6.

28. Nilsson D, Gustafsson PE, Svedin CG. Self-reported potentially traumatic life events and symptoms of post-traumatic stress and dissociation. Nord J Psychiatry. 2010;64:19-26. 
29. Birmes P, Brunet A, Carreras D, Ducassé J-L, Charlet J-P, Lauque D, et al. The predictive power of peritraumatic dissociation and acute stress symptoms for posttraumatic stress symptoms: a threemonth prospective study. Am J Psychiatry. 2003;160:1337-9.

30. Candel I, Merckelbach H. Peritraumatic dissociation as a predictor of post-traumatic stress disorder: a critical review. Compr Psychiatry. 2004;45:44-50.

31. Nilsson D, Svedin CG. Dissociation among Swedish adolescents and the connection to trauma: an evaluation of the Swedish version of Adolescent Dissociative Experience Scale. J Nerv Ment Dis. 2006;194:684-9.

32. Wolfradt U. Dissociative experiences, trait anxiety and paranormal beliefs. Pers Individ Dif. 1997;23:15-9. doi:https://doi.org/10.1016/S0191-8869(97)00043-3.

33. Spitzer C, Klauer T, Grabe H-J, Lucht M, Stieglitz R-D, Schneider W, et al. Gender Differences in Dissociation. Psychopathology. 2003;36:65-70.

34. Shin J-U, Jeong SH, Chung U-S. The Korean Version of the Adolescent Dissociative Experience Scale: Psychometric Properties and the Connection to Trauma among Korean Adolescents. Psychiatry Investig. 2009;6:163-72.

35. Sar V, Yargiç LI, Tutkun H. Structured interview data on 35 cases of dissociative identity disorder in Turkey. Am J Psychiatry. 1996;153:1329-33.

36. Asscher JJ, Van der Put CE, Stams GJJM. Gender Differences in the Impact of Abuse and Neglect Victimization on Adolescent Offending Behavior. J Fam Violence. 2015;30:215-25.

37. Thompson MP, Kingree JB, Desai S. Gender differences in long-term health consequences of physical abuse of children: data from a nationally representative survey. Am J Public Health. 2004;94:599604. doi:10.2105/ajph.94.4.599.

\section{Figures}




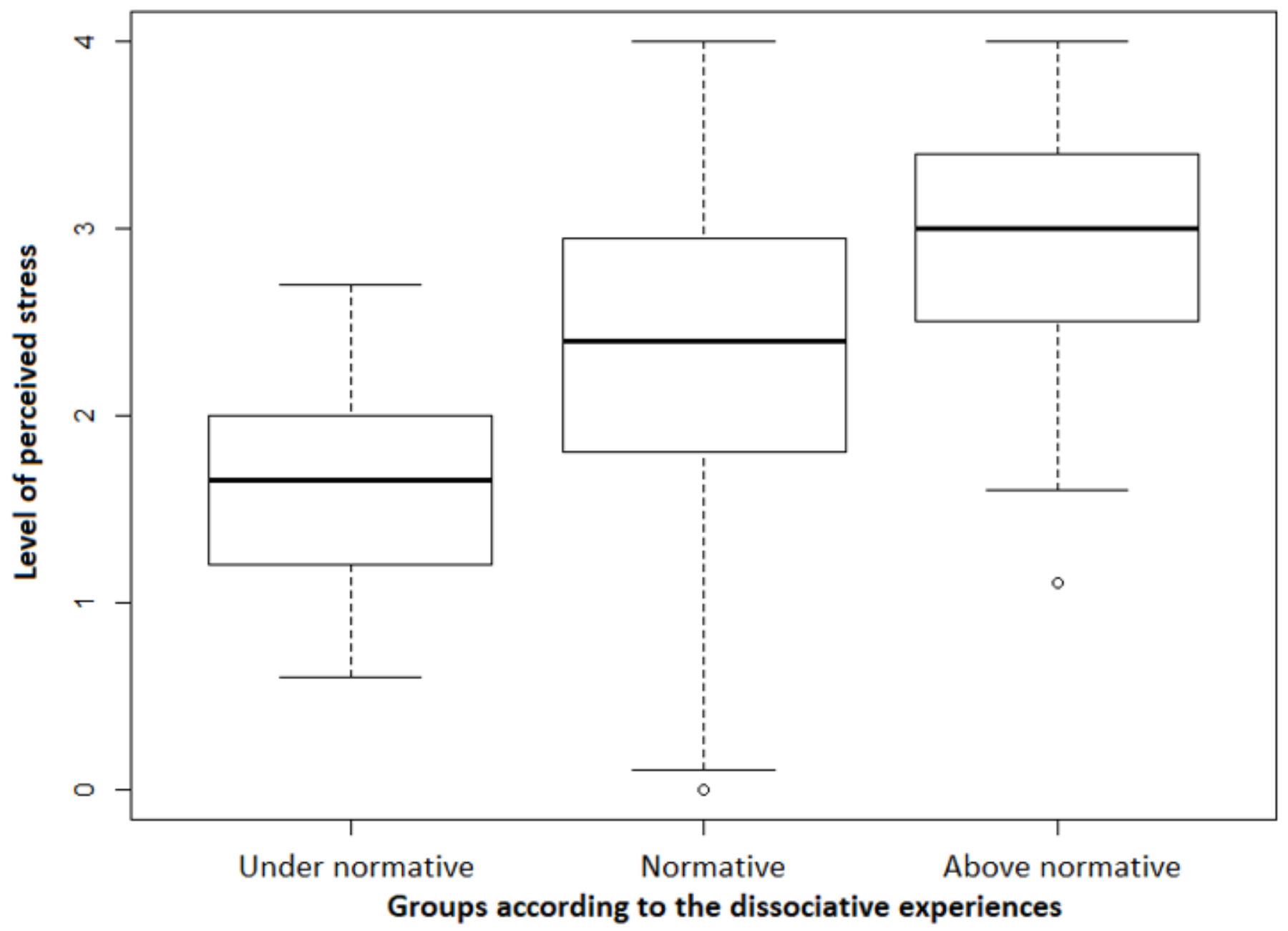

Figure 1

Hungarian students' groups according to the level of perceived stress Note. This figure demonstrates that among Hungarian students according to the emerging level of perceived stress the dissociative groups are trending from under normative to above normative groups. 


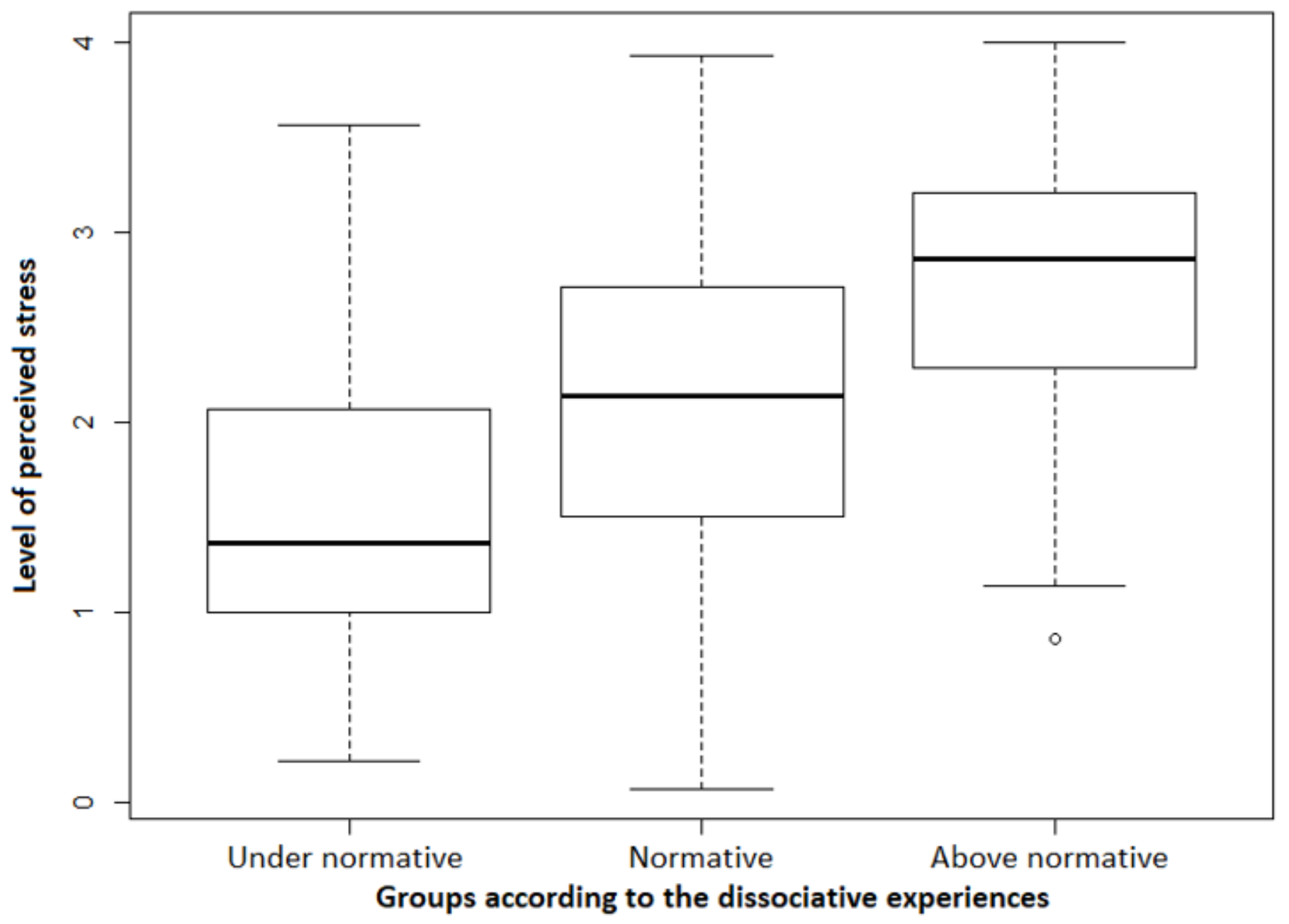

Figure 2

International students' groups according to the level of perceived stress Note. This figure demonstrates that among international students according to the emerging level of perceived stress the dissociative groups are trending from under normative to above normative groups.

\section{Supplementary Files}

This is a list of supplementary files associated with this preprint. Click to download.

- STROBEchecklistcrosssectional.docx 